\title{
Optical mercury sensing using a benzothiazolium hemicyanine dye
}

\author{
Sergio Tatay ${ }^{1}$, Pablo Gaviña ${ }^{1}$, Eugenio Coronado ${ }^{1}$ and Emilio Palomares ${ }^{1,2} *$ \\ (1) Instituto de Ciencia Molecular-Universidad de Valencia (ICMol-UV). Edificio de Institutos, \\ Polígono la Coma s/n. 46980 Paterna (Valencia), Spain. ${ }^{(2)}$ Institut Català d'Investigació \\ Química (ICIQ). Avda. Països Catalans, 16. 43007 Tarragona, Spain.
}

\section{epalomares@iciq.es}

\section{Synthesis of OMP}

3-(Carboxymethyl)-2-methylbenzothiazolium bromide was obtained in $60 \%$ yield by refluxing 2-methylbenzothiazole $(1.49 \mathrm{~g}, 10 \mathrm{mmol})$ with bromoacetic acid $(2.09 \mathrm{~g} 15 \mathrm{mmol})$ in toluene $(50 \mathrm{~mL})$ overnight. The reaction was cooled at room temperature and the resulting white precipitate was filtered, washed with toluene and dried in vacuo.

${ }^{1} \mathrm{H}$ NMR (DMSO- $\left.d_{6}, 300 \mathrm{MHz}\right): \delta 8.47$ (d, $\left.J=8.1 \mathrm{~Hz}, 1 \mathrm{H}\right), 8.29$ (d, $\left.J=8.2 \mathrm{~Hz}, 1 \mathrm{H}\right), 7.92-7.79$ (m, 2H), 5.77 (s, 2H), $3.19(\mathrm{~s}, 3 \mathrm{H})$.

A mixture of the benzothiazolium salt $(0.86 \mathrm{~g}, 3.0 \mathrm{mmol})$ and 4-diethylamino-2hydroxybenzaldehyde $(0.58 \mathrm{~g}, 3.0 \mathrm{mmol})$ in anhydrous ethanol $(75 \mathrm{~mL})$ was refluxed for $24 \mathrm{~h}$ in the presence of a catalytic amount of piperidine $(15 \mu \mathrm{L}, 0.15 \mathrm{mmol}) .{ }^{1}$ The reaction mixture was cooled to room temperature and the resulting precipitate was filtered, washed with diethyl ether and dried in vacuo, to yield OMP as a dark-green solid (1.18 g, 85\% yield).

Mp: $172-174{ }^{\circ} \mathrm{C} .{ }^{1} \mathrm{HRMN}\left(\mathrm{CD}_{3} \mathrm{OD}, 400 \mathrm{MHz}\right): \delta 8.20$ (d, $\left.J=15.0 \mathrm{~Hz}, 1 \mathrm{H}\right), 8.00$ (dd, $J=7.9$ and $1.0 \mathrm{~Hz}, 1 \mathrm{H}), 7.78(\mathrm{~d}, J=7.9 \mathrm{~Hz}, 1 \mathrm{H}), 7.67(\mathrm{dt}, J=7.9$ and $1.2 \mathrm{~Hz}, 1 \mathrm{H}), 7.63-7.54(\mathrm{~m}, 2 \mathrm{H}), 7.35$ (d, $J=15.0 \mathrm{~Hz}, 1 \mathrm{H}), 6.42(\mathrm{dd}, J=9.1$ and $2.4 \mathrm{~Hz}, 1 \mathrm{H}), 6.14(\mathrm{~d}, J=2.4 \mathrm{~Hz}, 1 \mathrm{H}), 5.25(\mathrm{~s}, 2 \mathrm{H}), 3.48$ (q, $J=7.1 \mathrm{~Hz}, 4 \mathrm{H}$ ), $1.23(\mathrm{t}, J=7.1 \mathrm{~Hz}, 6 \mathrm{H})$. HRMS (FAB): calcd for $\mathrm{C}_{21} \mathrm{H}_{23} \mathrm{~N}_{2} \mathrm{O}_{3} \mathrm{~S} 383.143$; found 383.144. 
NMR spectra for OMP:

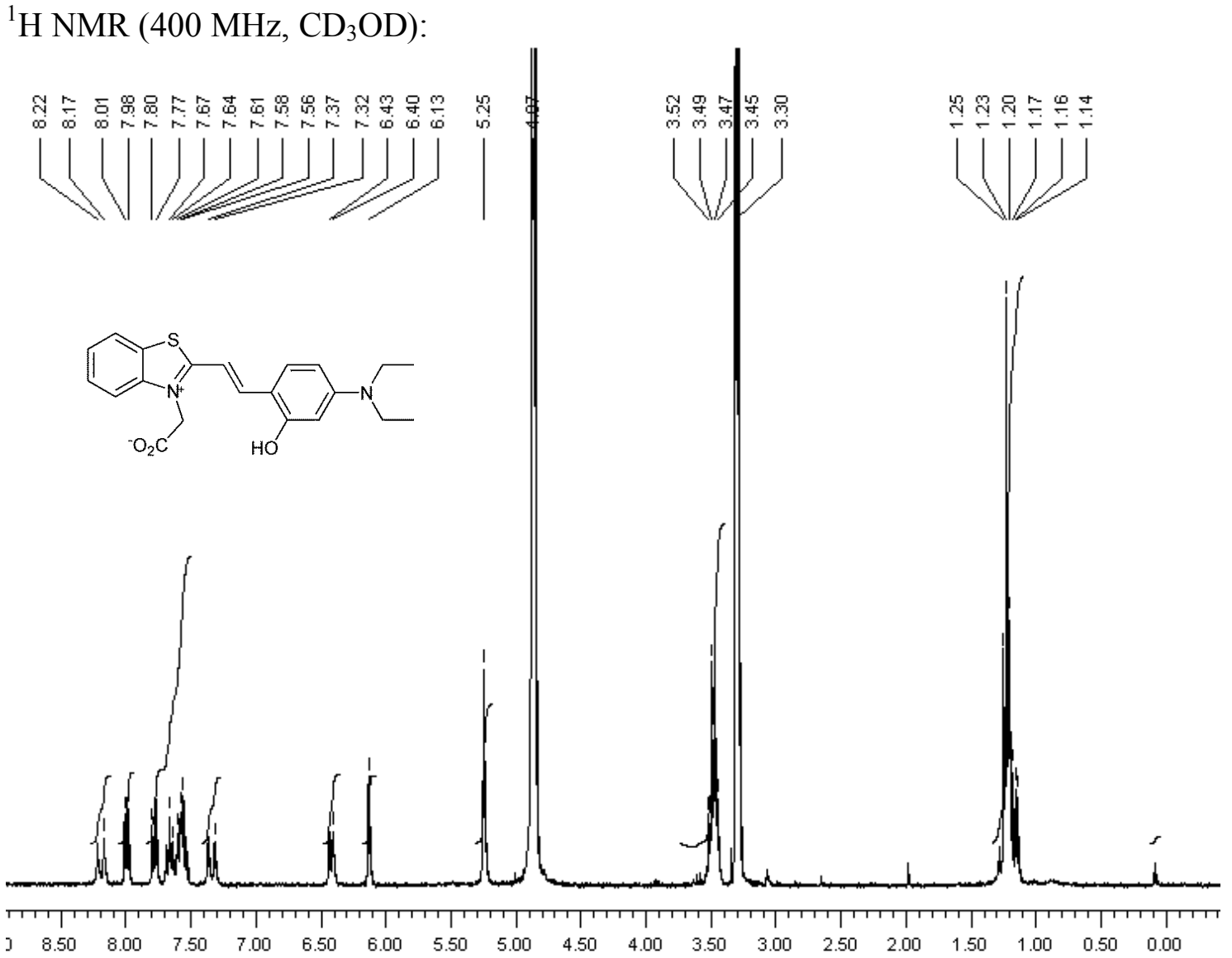

Figure S1 
${ }^{13} \mathrm{C}$ NMR and DEPT (400 MHz, $\left.\mathrm{CD}_{3} \mathrm{OD}\right)$ :

$13 \mathrm{C}$

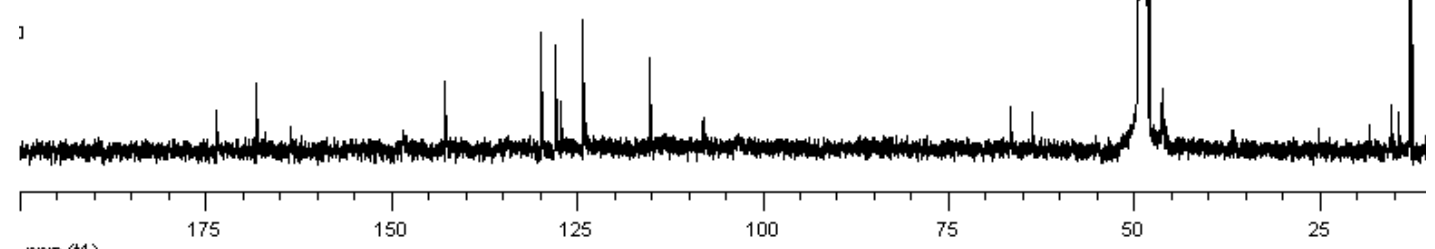

ppm (t1)

$13 \mathrm{C}$ dept
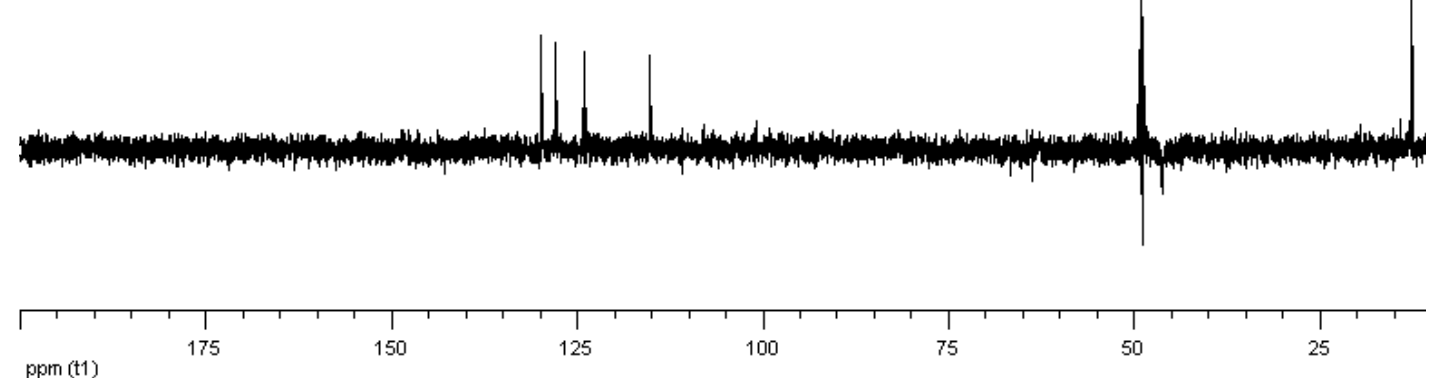

${ }^{13} \mathrm{C}$ NMR spectrum of OMP in $\mathrm{CD}_{3} \mathrm{OD}$ after 5000 scans. The low resolution of the ${ }^{13} \mathrm{C}$ NMR spectra is due to the low solubility of OMP in organic solvents.

Figure S2. 


\section{Determination of the complex stoichiometry and binding constant of the $\mathrm{Hg}(\mathrm{OMP})$} complex:

For the equilibrium

$$
M+n L \quad M L_{n} \quad K=\frac{C_{M L}}{C_{M} C_{L}^{n}}
$$

For the measurement of the absorbance of a series of different mixtures of $\mathrm{M}+\mathrm{L}$, prepared mixing different volumes of two solutions using the same concentration of $\mathrm{M}$ and $\mathrm{L}$ at constant volume, the corrected absorbance can be calculated as follows:

$$
A c=A-A^{\mathrm{o}}
$$

Where $A$ is the absorbance of the $\mathrm{M}+\mathrm{L}$ solution and $A^{\circ}$ the solution absorbance if a complex is not formed.

Working on a wavelength where $\varepsilon_{M}=0$ and using the Lambert-Beer law, $A c$ can be expressed as:

$$
A c=\left(\varepsilon_{M L}-\varepsilon_{L}\right) C_{M L}=\Delta \varepsilon C_{M L}
$$

Job's method states that if $A c$ is represented vs. ligand molar fraction $(X)$ a maximum in the corrected absorbance will be obtained when the following condition is accomplished

$$
n=\frac{1-X}{X}
$$

\section{It has been showed that in or case $n=1$.}

Moreover, we can express $\mathrm{M}$ and $\mathrm{L}$ concentrations for each $\mathrm{M}+\mathrm{L}$ samples as function of their initial concentration $\left(\mathrm{C}_{\mathrm{i}}^{\mathrm{o}}\right)$, if no complex is formed, and $\left(C_{M L}\right)$ for the actual concentration of the complex

$$
M=C^{\mathbf{o}}{ }_{M}-C_{M L} \quad L=C^{\mathbf{o}}{ }_{L}-C_{M L}
$$


Substituting in (1.1) and solving for $\mathrm{C}_{\mathrm{ML}}$

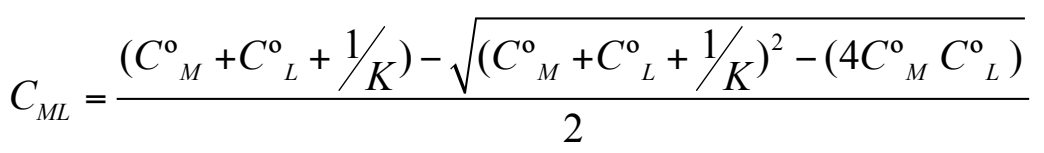

In this way $A c(1.2)$ can be expressed as a function of $\Delta \varepsilon$ and $C_{M L}$

$$
A c=\Delta \varepsilon\left(\frac{\left(C^{\mathbf{o}}{ }_{M}+C^{\mathbf{o}}{ }_{L}+1 / K\right)-\sqrt{\left(C^{\mathbf{o}}{ }_{M}+C^{\mathbf{o}}{ }_{L}+1 / K\right)^{2}-\left(4 C^{\mathbf{o}}{ }_{M} C^{\mathbf{o}}{ }_{L}\right)}}{2}\right)
$$

Adjusting experimental data to this equation using well known least squares methodology we can obtain $\mathrm{K}$ and $\Delta \varepsilon$.

\section{Reference:}

1. Chen, Y.-S.; Li, C.; Zeng, Z.-H.; Wang, W.-B.; Wang, X.-S.; Zhang, B.-W. J. Mater. Chem. 2005, 15, 1654-1661. 